\title{
Transposition
}

Musique et Sciences Sociales

\section{The Female-to-Male (FTM) Singing Voice and its Interaction with Queer Theory: Roles and Interdependency}

Alexandros N. Constansis

\section{OpenEdition}

\section{Journals}

Electronic version

URL: http://journals.openedition.org/transposition/353

DOI: 10.4000/transposition.353

ISSN: $2110-6134$

Publisher

CRAL - Centre de recherche sur les arts et le langage

\section{Electronic reference}

Alexandros N. Constansis, « The Female-to-Male (FTM) Singing Voice and its Interaction with Queer Theory: Roles and Interdependency », Transposition [Online], 3 | 2013, Online since 01 March 2013, connection on 19 April 2019. URL : http://journals.openedition.org/transposition/353 ; DOI : 10.4000/ transposition.353

This text was automatically generated on 19 April 2019

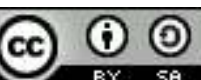

La revue Transposition est mise à disposition selon les termes de la Licence Creative Commons Attribution - Partage dans les Mêmes Conditions 4.0 International. 


\title{
The Female-to-Male (FTM) Singing Voice and its Interaction with Queer Theory: Roles and Interdependency
}

\author{
Alexandros N. Constansis
}

1 There are limited types of singing vocality which have been brought to public attention as a result of combined musicological, scientific and gender/queer theory advances of the last decades. The Female-to-Male transsexual voice is one of those recently discovered kinds of human vocality, and it has been made more accessible and predictable mostly as a result of hormonal administration and medical support. However, even though "Medicalization" has allowed trans people "to acquire therapy and social acceptance, transgenderism is part of a larger social struggle between defenders of the 'natural'... and the right of individuals to control their own bodies and define their own lives." ${ }^{1}$ The singing male trans vocality, or transvocality, is a significant yet overlooked aspect of this battle, which is frequently misrepresented solely as the result of recent scientific developments. Nonetheless, despite having been only recently recognised by the scientific and wider community, male transvocality was, to a certain extent, achievable prior to scientific advances by using herbal support and differential vocal placement. ${ }^{2}$ The latter is a term, which usually indicates the results of vocal misuse and only rarely a carefully adapted technique. As stated by Moya L. Andrews based on D. Kenneth Wilson, ${ }^{3}$ vocal misuse is often characterised by inappropriate use of pitch or volume. This type of misuse is often responsible for the long-term detrimental effects on the Female-to-Male voice.

2 The vocal persona cannot be disassociated from developments in the general persona of the trans individual. As stated above, both of these have become more controllable and dependable thanks to endocrinological interventions, such as the introduction of bioidentical hormonal supplements. Even so, the use of bioidentical hormones is not void of controversy. ${ }^{4}$ Irrespective of the efficacy and lasting effects of bioidentical hormonal solutions, Female-to-Male transvocality behaves in a less conventional manner than standard adult or other types of changing cisgender vocality, such as those encountered 
during male adolescence or female menopause. As explained in "The Changing Female-toMale (FTM) Voice", certain "parameters, such as testosterone receptors and cartilage response in adult transitioning larynxes, can create further drawbacks. [...] Anyone dealing with FTM voices should understand that the vocal reactions to artificial testosterone are rarely stable or smooth, especially during the first year. The vocal practitioner needs to be able to anticipate these effects as well as any added obstacles." 5 These aspects of the FTM Voice have only been partially assessed, mainly through recent acoustical observations and analysis $(2012)^{6}$ as well as medical examinations of this researcher's larynx and vocal folds, using techniques such as stroboscopy (2010). ${ }^{7}$ Even though this topic is going to be addressed within the next two years, from a singing practitioner's and musicologist's viewpoint, there is enough evidence to support the above hypotheses. The data has been collected as part of the continuing "Female-to-Male Singing Voice" programme, first conceived in 2002. Variant physiological aspects would need to be taken into consideration before composing any FTM vocality associated programme or investigating related outcomes. The results of the research on FTM voice have been shaped by all aforementioned elements.

\section{Queer Theory and Scientific Methods : Challenging Everyday Concepts and Perceptions}

3 Even though the characteristics of Female-to-Male vocality, speaking or singing, are frequently presented as the direct result of medical developments, scientific studies were not particularly concerned with singing results before 2002. The few works that briefly mentioned female-to-male singing vocality only recognized existing difficulties -in particular, "the adverse effect of the hormone therapy on singing capacities"8 - but did not offer solutions. Consequently, the development of the Female-to-Male singing voice cannot be attributed to these studies. Instead, we should look at concurrent advances in gender / queer theory and, even more prominently, at the direct involvement and works of credible trans artists, scientists and practitioners from a variety of fields, amongst them being this researcher / practitioner's study. ${ }^{9}$ Despite the involvement of queer and trans academics, artists and practitioners in theoretical debates and challenges, singing transvocality has still received unwanted attention, even within gender / queer studies. ${ }^{10}$ Significant yet not strictly comparable events, such as the presentation of Antony Hegarty (Antony and the Johnsons) with the British Mercury Award in 2005, brought a substantial level of mainstream attention to the male-identified transgender and, subsequently, transsexual singing vocality. ${ }^{11}$ As mentioned by Jodie Taylor, this was not because "queer narratives" did not exist before but "because until relatively recently, it has not been in the interest of social morality to publicize, let alone celebrate, sexual difference and queer lifestyles". ${ }^{12}$ However within the singing community this has been the case since the early 20th century. Particularly within popular genres, as claimed by Aaron Lecklider, audiences have been presented with "an arena where marginalized voices can be heard and sexual identities shaped, challenged, and renegotiated". ${ }^{13}$ This above view, however, undeniably presents us with a limited musicological and queer studies perspective because it ignores the role of historical singing phenomena, such as the castrati of the "Baroque" era, and their contribution to queer narratives, long before the introduction of Gender / Queer studies. 
Before continuing with the most substantive contribution to Female-to-Male singing vocality, i.e., its methodology, we need to remind ourselves of the importance of medical advances in recent years. Particularly, the introduction of bioidentical or biocompatible body regulating chemicals in the early 1990s form a contrast to the earlier inadequate or harsh forms of hormonal administration. These recent hormonal developments have made the Female-to-Male singing vocality more accessible and manageable. As we will discuss in the following section, the accessibility and manageability of the final vocal result appears to be reliant on the method of hormonal initiation : gradual vs. abrupt. However, there is the need to mention that in cases of unsuccessful vocal transition the provision of voice and communication therapy can help the transmale singer significantly. ${ }^{14}$ On rare occasions, someone could also consider the option of surgical intervention, such as the Thyroplasty type III according to Isshiki et al. ${ }^{15}$ Nonetheless, since the FTM voice is already compromised in terms of power, volume and dynamics when compared to the relatively analogous cisgender voices, the above surgical technique, known to result in weaker overall volume, should be treated as mostly applicable to speaking vocality. Even then, it should only be used as a last resort if the recommended voice and communication therapy does not produce the anticipated results.

\section{The Changing Female-to-Male Vocality}

Singing transsexual men ${ }^{16}$ have long been advised that "unpredictable and irreversible" changes in their vocality "may be significantly detrimental to vocal performance." ${ }^{17}$ The validity of the above medical assessment in terms of vocal performance has only recently been challenged. Irrespective of this though, the specific character of these vocal changes can be attributed to three significant transitional elements : the abrupt method of hormonal administration, the generalised care provision for transsexuals and the attitudes towards transvocality.

\section{Abrupt Hormonal Administration}

6 Despite the presence of international variations in the prescribed hormonal regime, most transmen in the UK and Europe tend to begin with the highest recommended intake. ${ }^{18} \mathrm{In}$ the US, however, there is a more individualised approach. ${ }^{19}$ Though the recommended intake in Europe has been changed since March 2003, ${ }^{20}$ the arguments behind abrupt testosterone administration for FTM transsexuals have not been challenged sufficiently due to issues associated with cost and waste. This is especially true when transition is prescribed on testosterone undecanoate (TU) or Nebido. TU is "a long acting formulation for i.m. [intramuscular] injection (which) requires significantly less frequent injections than other established [...] testosterone ester formulations." ${ }^{21}$ This type of injection is used increasingly in Europe and internationally but, to the best of my knowledge, is not yet administered in the USA. The remaining reason for the generalised transition on the highest available dosage is that it will produce the sort of testosterone levels which are able to effect maximum masculinisation of the voice and body within the minimum possible time. ${ }^{22}$ But quite apart from concerns about vocality, this process does not allow time for adjustment and, as such, may be susceptible to long-term adverse health effects. Let us note here, however, that lower doses, either in the UK or abroad, have been 
associated with medical bias against the trans community. The standing prejudice has been acknowledged by medical practitioners who have indicated that "doubts about the integrity of transgender individuals and the authenticity of gender dysphoria as a diagnosis [...] may lead some members of the medical profession to withhold treatment or prescribe inadequate doses of cross-sex hormones on safety grounds." ${ }^{23}$

\section{Generalised Care Provision for "Inconvenient Patients"}

7 Abrupt hormonal administration is the by-product of insufficiently individualised care provision for transpeople worldwide. Until recently, specialised "treatment" resembled a strange single-choice questionnaire where gender-variant individuals had to tick the "right" boxes, for instance, by presenting themselves as "heterosexuals" in orientation, in order to obtain hormonal and other transitional support. Although changes in legislation, such as the Gender Recognition Act 2004 in the UK, ${ }^{24}$ transformed most relevant health care provision, this has not necessarily been accompanied with a change in attitudes among mainstream care providers. Abuses and injustices towards transsexuals are less detectable in 2013, but this does not imply that discriminative or judgemental attitudes are not still common. There is evidence to demonstrate that the transsexual individual is still being treated as an inconvenience by many general health care providers in the UK and worldwide. ${ }^{25}$ Despite the presence of significant studies, such as Whittle et al., ${ }^{26}$ fullscale research is needed to record the changes, as well as the hidden implications, brought about by the introduction of significant pieces of legislation during the last decade. $^{27}$

\section{Attitudes towards Female-to-Male transvocality}

Despite FTM persons being warned about the dramatic effects testosterone will have on their voice, this researcher had not encountered in $2002-2003^{28}$ any transman who had been given means to deal with his changing speaking, let alone singing, vocality. The general consensus, even until relatively recently, had been that transmen's voices will "drop" sufficiently with only the presence of testosterone. Apart from this being unfair to transmen, it is also evidently simplistic. As demonstrated by Van Borsel et al. in 2000, results obtained from 16 individuals (sample survey) "and longitudinal data from two clients' suggested that speaking voice change was 'not always totally unproblematic". ${ }^{29}$ For this reason the researchers recommended voice assessment and counselling before the introduction of hormone therapy. Even so, the consensus remained unaffected due to limited understanding of all the parameters influencing male transvocality. There was no research on singing FTM voices before or during my own transition. Therefore, I had to look for material that described the closest equivalent process : the changing singing vocality of adolescent biological males. Based on the range of available studies, primarily by John Cooksey, and after finding a doctor who would agree with a more individualised provision, I tried to replicate the adolescent's changing hormone regime with the introduction of low start / gradual increase testosterone intake. The results of low testosterone for transitioning transmen have been perceived to be socially and psychologically detrimental due to their inability to "pass" successfully and, as such, their proneness to discrimination. In my case though, the decision was based on my teaching and performing background in singing. Simultaneously, I started devising a suitable 
method for developing my voice from vocal techniques with which I was already conversant. ${ }^{30}$

The Changing FTM Voice study hypothesis is not only supported by versatile research on adolescent and adult, as well as older cisgender, voices but also considered common knowledge among singing practitioners. All the evidence shows that abrupt hormonal changes are never beneficial to the vocal instrument. ${ }^{31}$ However, I do not underestimate the effects of social isolation or endangerment as a result of unsuccessful "passing" during transition..$^{32}$ Despite the irrefutable difficulties identified in several studies, "the loss of singing ability is far from inevitable" for FTMs..$^{33}$ The results of the ten-year participation in the FTM voice programme have demonstrated that "a combination of the right gradual testosterone intake together with soft exercising of the voice may not only help the voice to retain its singing quality, but also to acquire a new and very aesthetically pleasing quality." ${ }^{134}$ This is applicable even to those aged beyond their thirties at transition. However, this is not to imply that there are no matters of concern or limitations for this type of vocality. For instance, those with a classical or operatic singing background would need to accept an important constraint: Female-to-Male bodies would be highly unlikely to develop and support a masculine voice of operatic scope. There are several reasons for this. For instance, Female-to-Male thoraxes are, on average, smaller than those of biological males and, as such, have less capacity and power when singing at low ranges. However, in spite of this, many programme participants have affirmed that, with appropriate support, they were able to perform "neighbouring" types of repertoire, such as Lieder and Art Songs. ${ }^{35}$

\section{The Developing Voice: Performance Prerequisites and Suggestions}

No classical or art song compositions have been created with Female-to-Male transvocality in mind. The singer is, therefore, obliged to utilise repertoire which, in the best case scenario, is only relatively suitable for his type of vocality. The attempt to perform works originally composed for a different voice category -even a relatively similar voice type but at a different or more advanced developmental stage- is known to be an incredibly demanding task, which, at times, can prove detrimental. ${ }^{36}$ The effect of singing unsuitable repertoire is exacerbated when dealing with hybrid vocality ${ }^{37}$ and, in particular, Female-to-Male vocality, even if the ranges appear to be similar to those of biomale singers. As such, the need to safeguard this type of voice by developing specific techniques and individualised approaches is of paramount importance. These methods have so far been formed by taking body type as well as vocal range and tonal centres into consideration.

11 The methodology described is the one I followed in my dual role as voice researcher and a singing FTM. This stage is demonstrated in Case Studies 1 and 2, which include the results from four participants of the Developing FTM Voice programme. ${ }^{38}$ In the first stages, several variant approaches were used in order to assist male transsexual vocality. However, though some of them have been retained in the process, the most significant developments have been the result of a series of more controlled assessments conducted after the end of the previous phase. Those tests demonstrated, particularly in the early Developing Voice stages, that there is a need for performance dynamics adjustment in all 
sections of a given score. In addition, they established the need for a less overwhelming type of accompaniment, such as that produced by a guitar. This was based on earlier recordings and measurements which confirmed the research hypothesis and documented that accompaniment instruments characterised by softer tonal quality, e.g., the guitar, were inherently friendlier to male transvocality than those possessing a louder resonance, such as the piano. ${ }^{39}$ Nonetheless, since variant instrumentation is not always feasible, a good quality and discreet kind of amplification should also be considered. ${ }^{40}$

Vocal centre differentiation is a known characteristic of all changing vocality. As discussed in Constansis, this differentiation is, particularly, common to all hybrid vocal personae. ${ }^{41}$ In particular in the Female-to-Male voice, this discrepancy will continue to influence the transvocal persona noticeably, even post-transition. Therefore, another indicated performance approach involves art song transposition to a lower key, on average by one and a half tones. ${ }^{42}$ This method allows the songs to become more appropriate for the variant tonal centres. Unlike cisgender singers, the transmale vocalist will also sound better when the song is transposed. As demonstrated in Case Study 1, only the technically adept FTM singer is able to conquer an art song in the key for which it was originally composed, i.e., the one meant for cisgender vocalists. Nonetheless, even in this case, the singer's voice will be more sonorous and effective when the singer is allowed to utilise a more suitable key for his type of vocality.

This vocal centre differentiation provides just one reason for the distinction between variant vocality, including the FTM one, and cisgender singing. Another significant factor is the vague comparison between range and timbre when referring to transmale vocality. For instance, a participant singer's timbre may resemble that of a baritone. However, the voice does not behave like that of an average baritone because the singer does not exhibit the expected clarity or equivalent power in certain areas of his range. Moreover, in spite of possessing a reasonably good singing technique, the average voice breadth is likely to be limited and with a characteristic weakness in the upper and lower ends of the range in comparison to that of a typical cisgender singer. Finally, the voice timbre behaviour is not entirely uniform and, frequently, a bass-like voice character will change into that of a tenor-baritone in order for the singer to reach his higher range. This cannot be remedied by additional abdominal appoggio due to the singer's skeletal and muscular limitations. ${ }^{43}$ For these reasons, the attempt to describe the transmale vocalist by the application of biomale vocal categorisations seems not only rather inadequate but also misleading. Furthermore, in terms of Queer Theory, the utilising of cisgender vocal range terminology tends to negate the transmale singer's individual gender experience and expression and, as such, it seems somewhat inappropriate. There is clearly the need to apply differential terms, such as hybrid baritone, trans or variant tenor etc. However, the above terms would need to be chosen carefully by the singers themselves. If it is not possible to standardise the terminology, then any oral or written presentation should reflect the singers' views and gender perspectives accurately and respectfully.

\section{Case Study 1}

Four bilingual participants contributed to this Study, which was conducted online (via Skype). They included one Portuguese, one Italian and two English first language speakers. ${ }^{44}$ The music score used (Vaccaj, Exercise 1 , Part 1$)^{45}$ was initially performed in the published key (B flat). In order to prepare the singers, the same four basic warming 
up exercises ${ }^{46}$ were used. Subsequently, each singer "hummed" and then sang the vocal lines of Exercise No. 1 using the syllable "ma". This approach allowed the singers to focus only on the voice. Moreover, in terms of project design, the above helped to eliminate problems, such as native vs. foreign language pronunciation. ${ }^{47}$ Except for the warming up phase, the above process was repeated exactly in the keys of A, A flat and G. All four versions were recorded individually using Skype Recorder and then were carefully anonymised.

The Assessment Criteria were that each sample was to be evaluated in terms of intonation control, clarity and sonority. ${ }^{48}$ As part of this process, participants were asked to act as self-assessors as well as trained listeners. ${ }^{49}$ First, one hour after the completion of their recordings, participants were asked to self-assess their results using the above criteria. Following that, the recorded samples were anonymised, codenamed, categorized ${ }^{50}$ and then randomly mixed. In preparation for the next phase, the participants' self-assessed audio files were compared by the researcher against their codenamed records and then made available only to the remaining trained listeners. Second, one week later, each participant was asked to peer-assess the samples from three participants. ${ }^{51}$ The grading was performed, according to the assessment criteria and on a scale of $1-100 \%$. This result is found when the number of successful notes is divided by the total number of notes constituting the singing part of the score. ${ }^{52}$ Finally, one week later, all mixed and anonymised samples were finally assessed by the researcher. The reports from all sections were compared and the final grade of each sample was given. In addition to the participants feeling more at ease, the voices also reacted positively under these conditions and became more sonorous. The most successful of the mentioned keys in terms of participants and trained listeners' satisfaction was that of $G$. This is situated one and a half tones lower than the published version used by biomale baritones. ${ }^{53}$

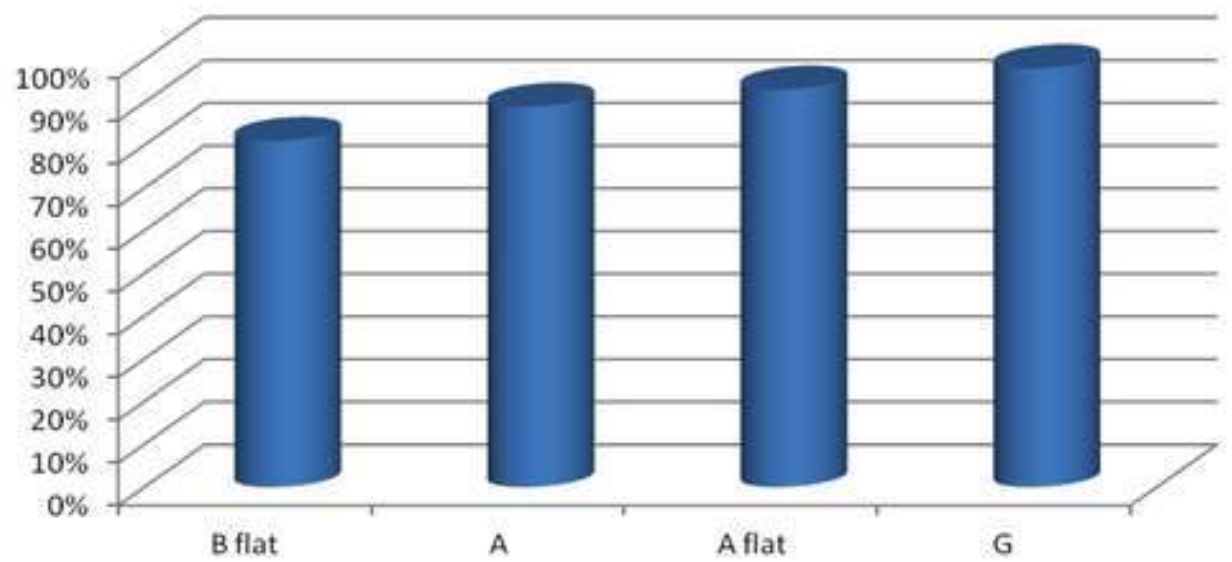

fig. 1

Case Study 1 (Graph) - Success Rates (on average) of 4 Participants' performing Vaccaj, Lesson 1 , Part 1 (Manca Sollecita) with a classical singing technique in 4 different keys (from B flat to G).

\begin{tabular}{|l|l|l|l|}
\hline B flat & A & A flat & G \\
\hline $81 \%$ & $89 \%$ & $93 \%$ & $98 \%$ \\
\hline
\end{tabular}

Case Study 1 - Success Rates (on aver.) 


\section{Case Study 2} Study 1 . The Aim, however, was to examine the ability of the FTM singing voice to achieve its existing post-transitional range without performing a pharyngeal widening, also known as laryngeal "drop". The condition of pharyngeal widening "seems to be met when the larynx is lowered, a gesture occurring typically in male professional Western operatic singing." ${ }^{44}$ The "drop", which is rarely used in more popular styles, appears to be a distinguishing factor for the vocal ability of the singing FTMs. Case Study 2 aimed to confirm and demonstrate the above. The method followed involved each participant's singing the said exercise in 4 keys (from B flat to $G$ ) without the use of the "larynx drop". As said, the latter is usually associated with classical singing projection. demonstrated problems of proper vocal fold closure and, as such, the presence of "air" (i.e., a "gap") and hoarseness were noticeable and, even, affected the next bar ( $\mathrm{n}^{\circ}{ }^{6}$ ), despite its lower tessitura. Bars 9-16 require from the singer, particularly the FTM one, to deal with long and demanding phrases. This necessitates strong breath control in order to unite imperceptibly the middle and upper registers. However, this was not achievable in bars 11-13 in B flat, unless the singers were to employ a very unsafe (i.e., "throat / screaming") technique. Participants were discouraged from applying it and so this specific exercise section was characterised by an audible "gap", i.e., a difference in phrasal clarity and sonority. Again, the next bar (no 14), though of lower range, was affected. Transposing the key, in a similar manner to that found in Case Study 1, produced improved results. Nonetheless, the only tonality which produced successful results by allowing the performance to remain stable and of similar quality throughout the piece was that of $G$.

The above results demonstrate that, without the application of a technique known as "laryngeal drop", the transposition of the original score (i.e., the one intended for biomale baritones) proves to be a necessity. This is because without the discussed downward transposition to the key of $\mathrm{G}$, the performance in a more popular singing style can produce neither successful nor comparable results in a score which is considered to be more demanding than usual..$^{55}$ Case Studies 1 and 2 are to be repeated by two other groups of participants in 2013.56 


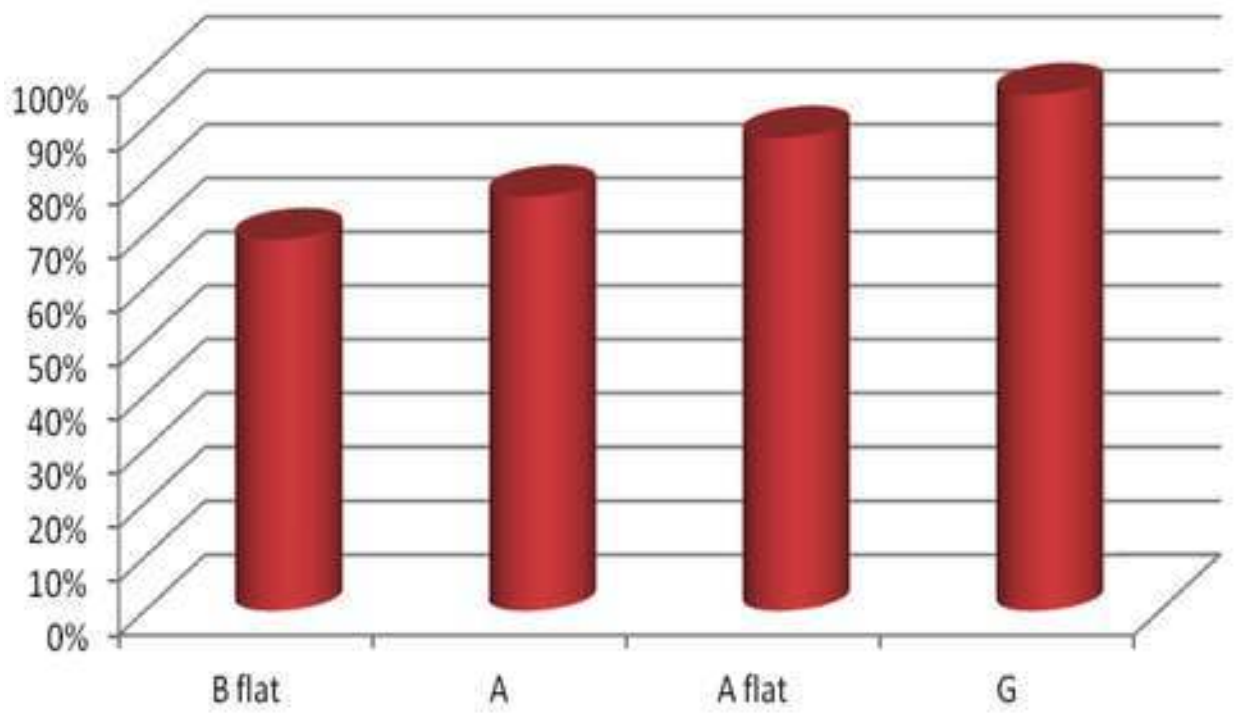

fig. 2

Case Study 2 (Graph) - Success Rates (on average) of 4 Participants' performing Vaccaj, Lesson 1 , Part 1 (Manca Sollecita) in 4 Keys (from B flat to G). No Use of Laryngeal Drop.

\begin{tabular}{|l|l|l|l|}
\hline B flat & A & A flat & G \\
\hline $69 \%$ & $77 \%$ & $88 \%$ & $96 \%$ \\
\hline
\end{tabular}

Case Study 2 - Success Rates (on aver.)

\section{Research Considerations}

Whereas the initial research (2002-2004) was carried out primarily from a singing teacher's perspective, ${ }^{57}$ established research results were also utilized to validate hypotheses. Nonetheless, the range of testing methods used for the programme was soon to be constrained by the participants' variant locations..$^{58}$ This is particularly demonstrated in the period between 2003 and 2006 when external laryngeal measurements were obtained directly from local participants. Simultaneously, there was a serious attempt for the same to be obtained indirectly from non-local participants, these latter having been given exact instructions on how to take their own measurements. ${ }^{59}$ But it soon became clear that there were discrepancies in the methods followed, despite the detailed descriptions and illustrations given. These inconsistencies affected the reliability of the results and their consequent usability in research reports. Since then, only data attained and processed by the researcher is recorded and analysed. The above problem demonstrates why the study on FTM singing vocality would benefit from replication under the observation of a multidisciplinary team that could test and validate given and newly-produced samples under controlled conditions. ${ }^{60}$ Ideally, the participants' international rather than local character, which has added generalisability in the existing results, should be retained in future research studies. 


\section{The Sense of Triumph followed by Complications}

Surviving a complicated vocal transition, such as Female-to-Male, makes the new vocal persona experience a sense of triumph against the odds. This, in this researcher's case, allowed the personal and professional life of the first post-transitional years to revolve around teaching individuals, demonstrating in groups and discussing scientific hypotheses and results. This truly creative period was dedicated by the researcher / practitioner to several academic and artistic projects. However, a singing voice tends to require constant attention by even the most professional and renowned singers. In this singer's case, problems started surfacing as a result of a particular medical history involving not only a radical change in hormonal regime ${ }^{61}$ but also in its methods of administration. Matters were also made more complicated by this practitioner's teaching and demonstrating in a truly wide vocal range. ${ }^{62}$ Neither issue has yet been assessed by other researchers / practitioners with a similar vocal background and would surely benefit from further investigation. ${ }^{63}$ However, since January 2010, the singer / practitioner has re-acquired his full singing capacity and also managed to improve his vocal volume and dynamics.

\section{Change of Hormonal Regime: Warning for Singers}

21 Any change in hormonal regime is likely to bring complications for the singing FTM. Following the doctors' recommendations, this singer / practitioner abandoned bimonthly Sustanon 250mg injections for twelve-weekly Nebido ones on December 2007. Apart from the user-friendly character of the slow-release injectable form, the recommendations were based on two significant reasons. Firstly, unlike earlier testosterone preparations, use of injectable testosterone undecanoate results in more balanced hormonal levels ${ }^{64}$ throughout the three-month period. Secondly, its chemical structure is almost identical to bio-testosterone.

Nonetheless, although most FTMs in Europe nowadays tend to either switch or start from Nebido, we still have limited knowledge of its full effects due to its relatively recent introduction. ${ }^{65}$ Despite the presence of several noted side-effects, ${ }^{66}$ these are frequently played down because of the kind of positive "aura" surrounding this type of injectable solution.

\section{Case Study: Constansis' Health and Vocal Account}

\section{The Health Account}

The years on testosterone have been healthier in general than the researcher's pretransitional days and with relatively few problems until 2007, such as increased red blood cells' counts. Even though, long-term androgen treatment can result to significantly higher haematocrit readings in FTMs, ${ }^{67}$ the noted increase made endocrinologists in UK and abroad to suggest the switch to Nebido. Within six months on the new regime, which started in December 2007, medical professionals were becoming increasingly concerned about the developing secondary polycythaemia. ${ }^{68}$ Until the middle of 2010, a neverending series of tests failed to reveal any reduction of the erythrocytes' number. ${ }^{69}$ The 
persistently high readings made endocrinologists to decrease the injection frequency from 12 to every 14 weeks as well as to monitor the condition on a regular basis. The frequency decrease, however, had until mid-2010 only reduced the testosterone levels and not the erythrocytes' count. The lower than average hormonal levels had produced several unwanted effects, including lower energy, severe insomnia and low calcium levels. ${ }^{70}$ The negative vocal effects could be considered as the result of several combined elements and would need to be examined in detail.

\section{The Vocal Account}

The change from Sustanon to Nebido did not prove kind to the practitioner's voice. Within three months of the first injection, the first side effects became noticeable: a combination of hoarseness with an unpleasant "metallic" quality located on the passagio from middle to higher register of the bass range. ${ }^{71}$ This, though not always present, was becoming increasingly noticeable and, therefore, problematic during the tuition of FTM participants. Since any change in medication and, particularly, in hormonal regime requires a period of body familiarisation and adjustment, the first period's side-effects, though unpleasant, were more or less expected. In this case, however, medical practitioners wrongly anticipated the secondary effects to be temporary. In the mean time, the falsetto range remained intact thus, most significantly, permitting the MTF and bio-female changing voices' research and teaching to continue unaffected. ${ }^{72}$ This was particularly useful since a lot of new participants joined either the Changing or Developing Male-to-Female Voice programme during that period.

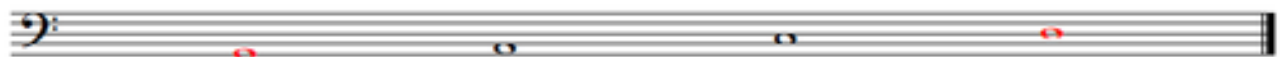

fig. 3

Example 1 - Vocal Range issues experienced after switching to Nebido.

The next months were particularly decisive for the lower range. The problematic third, instead of disappearing, started affecting the voice as if permanent. Additionally, the problematic area seemed to be expanding and becoming increasingly a fifth. ${ }^{73}$ The general health issues, explained earlier, also reduced the breathing capacity and the ability for effective appoggio, especially when standing. By the end of the summer 2008, the odd 'metallic' sound was giving place to the muffled sound of a "gap", typically appearing in an aging voice. Despite the researcher's non-typical voice history, this outcome is not something usually expected or considered by singers in their early forties. Similarly to the Changing Voice period, back in 2003-2004, there was the need to start investigating the causes, recording the data and developing hypotheses. This coincided with the vocal improvement, which started becoming more noticeable after May 2009.

\section{Working with other Musicians}

Every singer requires additional musical support in the form of coaching. However, even though the vocal differentiation was explained to two vocal coaches, there was a clear 
lack of consideration, for instance, in terms of adjusting the accompaniment dynamics for the session. As demonstrated in Case Studies 1 and 2, the "centres" of the FTM voice singing within lower male range tend to differ from their biomale analogues by one and a half tone on average. In the transmale, the associated high range limitations may be attributed to the inadequate development of vocal folds and larynx. For the same reasons, the upper limit is not compensated by an equivalent development of additional lower range ${ }^{74}$ Also, the less developed FTM skeleton in general and, particularly, the chest structure and musculature can be a serious impediment when applying the appoggioor "support". The first proper singing attempts post-transitionally tend to be confounded by the effects of a heavy new voice on a small, already established, body. ${ }^{75}$ This is an experience, unfortunately, rarely understood and mostly discredited by "outsiders". Nonetheless, this characteristic can truly explain why a rich type of accompaniment writing can prove particularly testing for the FTM vocal persona, especially when we bear in mind that no classical or art songs have ever been written with this kind of voice in mind. Therefore, if the coaching provided is either poorly adjusted or entirely unadjusted for the individual's needs, any attempts are likely to prove unsuccessful. For this reason, the ideal vocal accompanist for the FTM vocal persona would need to be not only someone musically adept but also with an in-depth knowledge of this particular vocal and general persona. This is, beyond doubt, a rare occurrence within trained musicians' circles. As such, assuming that a knowledgeable musician cannot be found either from within a trans-immediate or a closely-related environment, then an open-minded trainee singing accompanist, talented as well as considerate, will be the best available option. The practitioner has been working with the same undergraduate accompanist since January 2011. The first eight sessions mostly consisted of educating the pianist in the idiosyncrasies of the Female-to-Male singing vocality, especially in comparison to those exhibited by that of the average biological male with a similar range and timbre. A range of professional and private recordings of the singer's voice demonstrate a significant development in terms of volume, dynamics as well as general vocal control. ${ }^{76}$

\section{Discussion}

As Parker acknowledged in 2007, "there are few cultural representations of FTM, as opposed to MTF, transsexuals." ${ }^{77}$ Even though matters have improved, the weakness of FTM versus MTF sample in terms of artistic and vocal 'visibility' is not yet sufficiently challenged. As such, this work would like to encourage further participation as well as scientific investigation on this rare type of hybrid singing vocality.

\section{Vocal and Musicological Issues}

There is the need, as said, for further education for FTM singers, as well as composers and music coaches. The reason singers need to be included here is because many continue to ignore the parameters of their individual vocality and use inappropriate standards of exercising or singing for their present status. One of the major difficulties for male transvocal personae is for them to realise the need to change their method of singing to a "supported" one in order to retain both their singing ability long term as well as improve their capacity. ${ }^{78}$ Once Female-to-Male singers know the idiosyncrasies of their individual instruments, the composers would be more likely to be involved and the music coaches 
more willing to listen. Most importantly, however, this is the way that transmale hybrid vocal personae will be able to achieve freedom from binarian standards and, therefore, respect for themselves and their audiences.

\section{The Role of Queer Theory in FTM Voice's Future Development} musicology is still considered to be in its infancy (Lewis, 2009). ${ }^{79}$ This statement, however, does not imply the lack of important publications or experimentation with the concept of queer performance and sound. It rather implies that the number of queer musicological works and their impact remains accessible only within the field. In addition, a significant majority of the studies dedicated to "queer performative embodiment" tends to focus "on visually manifested utterances, rather than auditory ones." ${ }^{10}$ This is not the case with the Female-to-Male Voice study and programme, which concentrates on revealing the timbre and preserving and developing the auditory idiosyncrasies of these unique vocal personae. Their individuality is mostly associated with their ability to exceed the boundaries. As stated by Butler, "to go from F to M, or from M to F, is not necessarily to stay within the binary frame of gender, but to engage transformation itself as the meaning of gender". ${ }^{81}$ This is particularly applicable to male transvocality, which, despite existing hindrances, is fascinating for a variety of reasons; among them the ability to possess and reflect non-binarian gender experiences.

Transmale vocal frequencies are equally the outcomes of transcending perspectives and a variant thoracic and laryngeal anatomical development. Despite their uniqueness, however, they are not yet experienced widely by audiences due to several contributing factors. Among them, we should name the preconceived ideas of certain audiences as well as many transmale singers' lack of confidence. The above example is directly related to the singers' experiences of prejudice as well as widespread perceptions and misconceptions of transpeople as outcasts. For the reasons explained in this article, the music and artistic fields would need to be liberated from the above clichés before being able to appreciate the transvocal groundbreaking instrument as a whole. The current progress in male transvocality is, however, directly related to achievements in Queer Theory / Musicology and, most importantly, by FTMs themselves. Transmen who believed in themselves and realised that, despite the usefulness of acquiring knowledge and techniques via the general community, these inputs are likely to lack the inner circle's insight. Whereas it is not unknown for classical singing students to work with teachers of the same voice type, in the transmale voice the insider practitioner has a more significant role to play. This is because, apart from the ability to demonstrate using the same register, teachers of trans singing background can also understand, in depth, the singing transmen's struggles under hormones or in relation to "binding" and surgery. This is the reason that, despite the usefulness of acquiring help ex cathedra, singing FTMs have been able to succeed more since, empowered and enabled by Queer and Transgender Theory, they have started obtaining and developing the necessary skills for themselves. Though this is only the beginning of a long and unnerving road for male transvocality, there is also a growing realisation: becoming oneself is directly associated with "a performance of internal visualisation." 82 This involves knowing the history of Trans Queer movement and non-binarian vocality in depth. Apart from respecting the safe singing principles at all times, the process necessitates researching, developing and presenting the specific vocal 
characteristics to audiences worldwide. The continuing work on FTM voice has started demonstrating that, metaphorically as well as literally, "it is (truly) up to (FTMs) to make (their) voices sing." ${ }^{83}$

Acknowledgments: I would like to thank Prof. David M. Howard (Head of Department of Electronics, University of York, UK) and Dr John Potter (Reader Emeritus in Music, University of York, UK) for their valuable support. Also, Dr Fiona Shaw (Lecturer in Creative Writing, Northumbria University, UK) and Daniel Jones for their editorial help.

\section{Appendix}

\section{Case Studies $1 \& 2$ - Material}

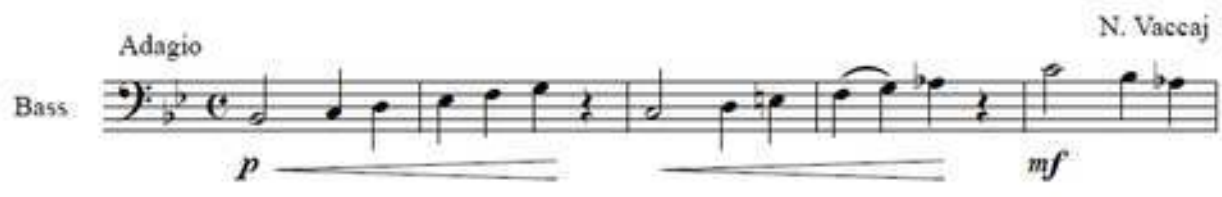

B

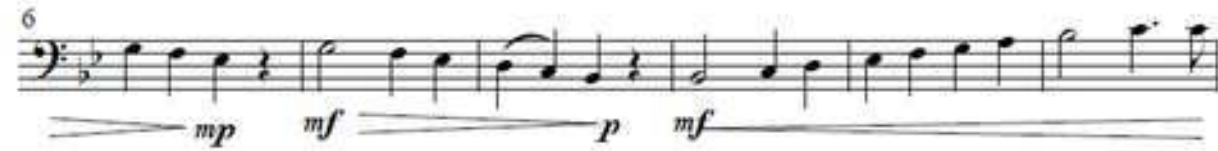

B

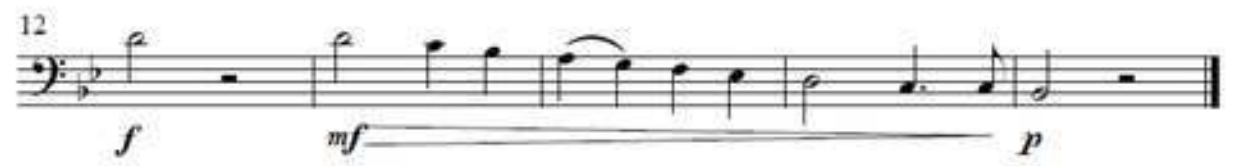

fig. 4

N. Vaccaj: Metodo Pratico di Canto [Practical Method of Singing] (Lesson 1, Exercise 1).

B flat is the published key for Baritone (Cf. Ricordi Editions, 1990, p. 9). For the purpose of Case Studies 1 and 2, however, the vocal score is also lowered gradually and performed in three consecutive keys; four keys in total. This is achieved by transposing the exercise by a semitone each time, i.e., from B flat to $A$, then $A$ flat, until the key of $G$ is reached. No higher keys are used. This is because the original key (B flat) proves demanding enough for the majority of FTM participants who sing in the bio-baritone range. The FTM Voice Programme and this researcher would never compromise the participants' vocal health and wellbeing for research or any other purposes. 


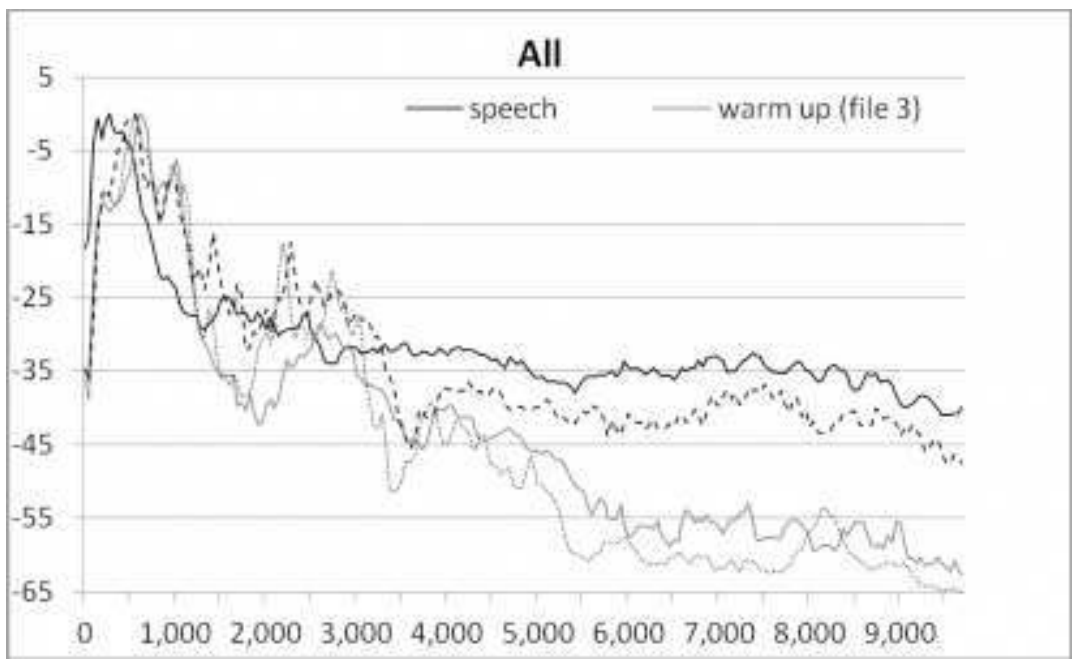

Unpublished Case Study [in progresse] (2012-2013)

CASE STUDY (UNPUBLISHED): "THE PRESENCE OF A SINgER'S FORMANT IN THE SINgINg FEMALE-TOMALE (FTM) VOICE". RECORDINgS AND ACOUSTIC ANALYSES (LTAS) WERE CONDUCTED BY PROF. DAVID M. HOWARD (STAgE 1, JULY \& OCTOBER 2012).

\section{BIBLIOGRAPHY}

ABITBOL J, ABITBOL P, ABITBOL B, "Sex hormones and the female voice”, in Journal of Voice, Vol. 13, № 3, 1999, p. 426-446.

ADLER, Richard K., CONSTANSIS, Alexandros N., and VAN BORSEL, John, "Female-to-Male Transgender / Transsexual Considerations", in ADLER, Richard K., HIRSCH, Sandy, and MORDAUNT, Michelle (eds.), Voice Therapy and Communication for the TG/TS Client, 2nd Edition, San Diego, CA, Plural Publishing, Inc., 2012, p. 153-186.

ANDREWS, Moya L., Manual of Voice Treatment: Pediatrics through Geriatrics, 3rd Edition, San Diego, CA, Singular Publishing Group, 2006.

"Art song", in Grove Music Online, Oxford Music Online, http://www.oxfordmusiconline.com/su..., 2012 (Accessed 07.08.2012).

BENJAMIN, Harry, The Transsexual Phenomenon, New York, The Julian Press Publishers, 1966.

BONENFANT, Yvon, "Queer Listening to Queer Vocal Timbres", in Performance Research: A Journal of the Performing Arts, Vol. 15, № 3, p. 74-80.

BRYSON, Paul C., BUCKMIRE, R.A, ROSEN, C.A, TALAVERA, F, KASS, E, SLACK, C.L, and MEYERS, A.D, "Stroboscopy", in Medscape Reference, June 16, 2011. Online: http:// emedicine.medscape.com/artic... (Accessed: 02.04.2012) BUTLER, Judith, Undoing Gender, London, Routledge, 2004.

CAMERON, Deborah, "Designer Voices", in Critical Quarterly, Vol. 43, № 4, 2001, p. 81-85. 
CONSTANSIS, Alexandros N., Hybrid Vocal Personae, PhD Thesis, York (UK), University of York, 2009.

CONSTANSIS, Alexandros N., "The Changing Female-to-Male (FTM) Voice", in Radical Musicology, Vol. 3, 2008. Online: http://www.radical-musicology.org.u... (Accessed: 19.10.2012).

CONSTANSIS, Alexandros N., "It's up to us to Make our Voices Sing", inVoiceprint - Australian Voice Association, 2008, p. 5-6.

COOKSEY, John M., and WELCH, Graham F., "Adolescence, singing development and national curricula design", in British Journal of Music Education, Vol. 15, № 1, 1998, p. 99-119.

Gender Recognition Act (GRA), Ch. 7, London, 2004, p. 1. Online: http://www.legislation.gov.uk/ ukpga... (Accessed: 02.04.2012).

GORTON, R. Nick, BUTH, Jamie, and DEAN, Spade, Medical Therapy and Health Maintenance for Transgender Men: A Guide for Health Care Providers. San Francisco, Lyon-Martin Women's Health Services, 2005.

GRANT, Jaime M., MOTTET, Lisa A., TANIS, Justin, HARRISON, Jack, HERMANN, Jody L., and KEISLING, Mara, Injustice at Every Turn: A Report of the National Transgender Discrimination Survey, Washington, National Center for Transgender Equality and National Gay and Lesbian Task Force, 2011.

GUGATSCHKA, Markus, "Sex hormones and the elderly male voice", in Journal of Voice, Vol. 24, № 3, 2010, p. 369-373.

HALBERSTAM, Judith, "The Anti-Social Turn in Queer Studies", in Graduate Journal of Social Science, Vol. 5, № 2, 2008, p. 140-156.

HEMBREE, W.C, COHEN-KETTENIS, P, DELEMARRE-VAN DE WAAL, H.A, GOOREN, L.J, MEYER III, W.J, SPACK, N.P, TANGPRICHA, V, and MONTORI, V.M, "Endocrine Treatment of Transsexual Persons: An Endocrine Society Clinical Practice Guideline", in Journal of Clinical Endocrinology and Metabolism, Vol. 94, № 9, 2009, p. 3132-3154.

HUGHES, James, "Beyond the medical model of gender dysphoria to morphological selfdetermination", in Lahey Clinic Medical Ethics Journal, Vol. 13, № 1, 2006, p. 10-12.

HOWARD, Martin, and HAMILTON, Peter J., Haematology, 3rd Ed., Edinburgh, London and New York, Churchill Livingstone, 2008.

ISSHIKI, N, TAIRA, T, and TANABE, M, "Surgical Alteration of Vocal Pitch", in The Journal of Otolaryngology, Vol. 12, № 5, 1983, p. 335-340.

JAMES, C, UGO, V, LE COUEDIC, J-P et al., "A unique clonal JAK2 mutation leading to constitutive signalling causes polycythaemia vera", in Nature, Vol. 434, April 2005, p. 1144-1148.

JOCKENHÖVEL, F, MINNEMANN, T, SCHUBERT, M, FREUDE, S, HÜBLER, D, SCHUMANN, C, CHISTOPH, A, and ERNST, M, "Comparison of long-acting testosterone undecanoate formulation versus testosterone enanthate on sexual function and mood in hypogonadal men", in European Journal of Endocrinology, Vol. 160, 2009, p. 815-819.

LECKLIDER, Aaron, "Introduction", in Journal of Popular Music Studies, Vol. 18, № 2, 2006, p. $117-250$.

LEVY, Andrew, CROWN, Anna, and RUSSELL, Reid, "Endocrine intervention for transsexuals", in Clinical Endocrinology, Vol. 59, 2003, p. 409-418.

LEWIS, Rachel, "What's Queer about Musicology Now?", in Women and Music: A Journal of Gender and Culture, Vol. 13, 2009, p. 43-53. 
LEWCOCK, Ronald et al. (signed by Sundberg, Johan), “Acoustics”, Grove Music Online, Oxford Music Online, http://www.oxfordmusiconline.com/su... (Accessed: 25.08.12).

MITCHELL, Martin, and HOWARTH, Charlie, Trans Research Review, Manchester, Equality and Human Rights Commission, 2009.

NIESCHLAG, Eberhard, and BEHRE, Hermann M. (eds), Testosterone, action, deficiency, substitution, Cambridge, Cambridge University Press, 2004.

NOBLE, Jean Bobby, Sons of the Movement: FtMs Risking Incoherence on a Post-queer Cultural Landscape, Toronto, Women's Press, 2006.

PARKER, Emma, "The Real Thing: Transsexuality and Manhood in Rose Tremain's Sacred Country", in Women: A Cultural Review, Vol. 18, № 3, 2007, p. 303-326, 303 \& 312.

POTTER, John, Tenor: History of a Voice, New Haven and London, Yale University Press, 2009.

ROSENTHAL, M. Sara, "Ethical problems with bioidentical hormone therapy: Ethics and bioidentical hormones", in International Journal of Impotence Research, Vol. 20, No. 1, January / February 2008, p. 45-52.

"Sonority", in LATHAM, Alison (ed.), The Oxford Companion to Music. Online: www.oxfordmusiconline.com/su... (Accessed: 23.08.12).

SPIEGEL, Jeffrey H., "Phonosurgery for Pitch Alteration: Feminization and Masculinization of the Voice", in Otolaryngologic Clinics of North America, Vol. 39, 2006, p. 77-86.

SUNDBERG, Johan, "Level and Center Frequency of the Singer's Formant", in Journal of Voice, Vol. 15, № 2, June 2001, p. 176-186.

SUNDBERG, Johan, The Science of the Singing Voice, DeKalb, IL, Northern Illinois University Press, 1989.

SWANSON, Frederick J., "The young male with a changing voice", in NATS Bulletin, Vol. 38, № 1, 1981, p. 32-34.

SWANSON, Frederick J., "Changing voices: Don't leave out the boys", in Music Educators Journal. Vol. 70, № 5, 1984, p. 40-50.

TAYLOR, Jodie, "Scenes and sexualities: Queerly reframing the music scenes perspective", in Continuum: Journal of Media \& Cultural Studies, Vol. 26, № 1, 2012, p. 143-156.

T'SJOEN, G, MOERMAN, M, VAN BORSEL, J, FEYEN, E, RUBENS, R, MONSTREY, S, HOEBEKE, P, DE SUTTER, P, and DE CUYPERE, G, "Impact of Voice in Transsexuals", inInternational Journal of Transgenderism, Vol. 9, № 1, 2006, p. 1-7.

T'SJOEN, Guy, Psycho-Endocrinological Aspects in Aging Males and Transsexual Persons, $\mathrm{PhD}$ Dissertation, Ghent, Belgium, University of Ghent, January 2006.

VAN BOREL, J, DE CUYPERE, G, RUBENS, R, and DESTAERKE, B, "Voice problems in female-to-male transsexuals", in International Journal of Language and Communication Disorders, Vol. 35, № 3, 2000, p. 427-442.

WILSON, D. Kenneth, Voice Problems of Children, 2nd Edition, Baltimore, The Williams and Wilkins Company, (orig. 1972) 1979.

WILCHINS, Riki Anne, Read my lips: Sexual subversion and the end of gender, New York, Firebrand, 1997. 
WHITTLE, Stephen, TURNER, Lewis, and AL-ALAMI, Maryam, "Engendered Penalties: Transgender and Transsexual People's Experiences of Inequality and Discrimination", in The Equalities Review, 2007. Online: http://www.pfc.org.uk/pdf/Engendere... (Accessed: 27.12.2010).

YASSIN, A.A, and SAAD, F, "Treatment of sexual dysfunction of hypogonadal patients with longacting testosterone undecanoate (Nebido $\left.{ }^{\oplus}\right)$, in World Journal of Urology, Vol. 24, 2006, p. 639-644.

ZITZMANN, M.N.E, and NIESCHLAG, E, "Long-term experience of more than 8 years with a novel formulation of testosterone undecanoate (Nebido) in substitution therapy of hypogonadal men", in Aging Male, Vol. 5, 2006, p. 5.

\section{NOTES}

1. HUGHES, James, "Beyond the medical model of gender dysphoria to morphological selfdetermination", in Lahey Clinic Medical Ethics Journal, Vol. 13, № 1, 2006, p. 10.

2. The results of herbal "medication" are negligible when compared to prescribed bioidentical hormones. Moreover, for some of the herbal alternatives, there is also concern about their long-term safety. Herbal-based "hormonal remedies", such as Tribulus Terestris, are still known to be used by transsexual men (transmen) during their early transitional stages, especially when obtaining testosterone legally is not an option.

3. ANDREWS, Moya L., Manual of Voice Treatment: Pediatrics through Geriatrics, 3rd Edition, San Diego, CA, Singular Publishing Group, 2006, p. 211; WILSON, D. Kenneth, Voice Problems of Children [1972], 2nd Edition, Baltimore, The Williams and Wilkins Company, 1979, p. 28.

4. Cf. ROSENTHAL, M. Sara, "Ethical problems with bioidentical hormone therapy: Ethics and bioidentical hormones", in International Journal of Impotence Research, Vol. 20, № 1, January/February 2008, p. 45-52.

5. CONSTANSIS, Alexandros N., "The Changing Female-to-Male (FTM) Voice", in Radical Musicology, Vol. 3, 2008, par. 32. Online: http://www.radical-musicology.org.u... (Accessed: 19.10.2012).

6. As part of a Case Study on the Developing FTM Voice (Stage 1: "The ability to achieve a Singer's Formant" completed, Stage 2: in progress), which was conceived by Constansis in 2012, specialised recordings of the researcher's voice were conducted by Prof. David M. Howard in July 2012 (Anechoic Chamber, University of York, UK). Recent acoustic analyses of the above recordings (October 2012) clearly demonstrate a singer's formant (see Graph 3 - Appendix). According to Johan Sundberg, the singer's formant "is a prominent spectrum envelope peak near $3 \mathrm{Khz}$, typically found in voiced sounds produced by classical operatic singers." SUNDBERG, Johan, "Level and Center Frequency of the Singer's Formant", in Journal of Voice, Vol. 15, № 2, June 2001, p. 176.

7. Stroboscopy or "video documentation of laryngeal anatomy along with its mechanical function" is claimed to be "a painless, office-based procedure". BRYSON, Paul C., et al., "Stroboscopy", in Medscape Reference, June 16, 2011, online: http:// emedicine.medscape.com/artic... (Accessed: 02.04.2012). However, the intervention is not painless unless performed under local anaesthesia, especially when common anatomical irregularities, such as nasal septum deviation, are present. Certain practitioners, however, frequently prefer performing this examination without anaesthesia. This 
attitude made most UK participants either withdraw before the completion of the examination or refuse to participate in this side of the programme.

8. VAN BORSEL, John, et al., "Voice problems in female-to-male transsexuals", in International Journal of Language and Communication Disorders, Vol. 35, № 3, 2000, p. 437.

9. The Changing FTM Voice study commenced in 2002 (active stage: March 2003-March 2004). The results of this researcher's first participation were presented in September 2004 at $6^{\text {th }}$ International Congress on Gender Identity: "Reflecting Genders", Manchester, UK.

10. Cf. HALBERSTAM, Judith, "The Anti-Social Turn in Queer Studies", in Graduate Journal of Social Science, Vol. 5, № 2, 2008, p. 140-156, and NOBLE, Jean Bobby, Sons of the Movement: FtMs Risking Incoherence on a Post-queer Cultural Landscape, Toronto, Women's Press, 2006.

11. Antony Hegarty's voice does not appear to have been influenced by HRT, i.e., testosterone administration. The singer presents as androgynous and identifies as transgender.

12. TAYLOR, Jodie, "Scenes and sexualities: Queerly reframing the music scenes perspective", in Continuum: Journal of Media \& Cultural Studies, Vol. 26, № 1, 2012, p. 148.

13. LECKLIDER, Aaron, "Introduction", in Journal of Popular Music Studies, Vol.18, № 2, 2006, p. 117.

14. For a range of suitable approaches, see ADLER, Richard K., HIRSCH, Sandy, and MORDAUNT, Michelle (eds.), Voice Therapy and Communication for the TG/TS Client, 2nd Edition, San Diego, CA, Plural Publishing, Inc., 2012.

15. ISSHIKI, N, et al., "Surgical Alteration of Vocal Pitch", in The Journal of Otolaryngology, Vol. 12, № 5, 1983, p. 335-340. As stated by Spiegel, the procedure involves "shortening of the anteroposterior length of the thyroid cartilage... [which] reduces the tension, reduces the length, and increases the vibratory mass of the cord, and thus, should lower the voice pitch substantially." SPIEGEL, Jeffrey H., "Phonosurgery for Pitch Alteration : Feminization and Masculinization of the Voice", in Otolaryngologic Clinics of North America, Vol. 39, 2006, p. 79. In nine male patients, there was significant pitch reduction ranging from "38 to $178 \mathrm{~Hz}$ " (Ibid.)

16. The term transsexual man is used in this article interchangeably with other terms, such as transman, Female-to-Male, FTM, male transsexual etc. The reader should note here that the term 'male transsexual' used to be applied inappropriately to Male-toFemale (MTF) transsexuals. Similarly, FTMs used to be referred to as 'female transsexuals' until very recently. The remaining exponents of the insulting terminology have been challenged during the works of the most recent Biennial Symposia of the World Professional Association for Transgender Health (WPATH). The gender-inconsiderate application of the stated terminology had been introduced by all significant forerunners, such as Harry Benjamin (The Transsexual Phenomenon, New York, The Julian Press Publishers, 1966, p. 30 and p. 84 and Richard Green and John Money, eds, Transsexualism and Sex Reassignment, Baltimore, Johns Hopkins, 1969) and was still perpetuated by many medical researchers until the last decade on average. The justification was that, based on a person's biological and genetical structure (XX or XY), the above terms were scientifically sound. Nevertheless, gender incongruence or 'transsexualism' is a priori defined as one person's inner conflict with their externally presented biological or genetical sex. The role of Gender / Queer Theory at remedying such theoretical as well as practical inconsistencies within the field has been enormous. As such, the use of 'male transsexual' in this article in its gender-appropriate format not only reflects the range of 
terminology applied to male-identified trans individuals but also, most importantly, serves as a statement and, simultaneously, as a stark reminder of recent history.

17. GORTON, R. Nick, BUTH, Jamie, and DEAN, Spade, Medical Therapy and Health Maintenance for Transgender Men : A Guide for Health Care Providers, San Francisco, LyonMartin Women's Health Services, 2005, p. 59.

18. For instance, intramuscular testosterone injections of 200-250 mg, administered every two weeks.

19. GORTON et al. (Medical Therapy and Health Maintenance for Transgender Men: A Guide for Health Care Providers, op. cit.) indicated that "injected testosterone [was] started at a range of doses (25-125 mg / week depending on the patient and clinician) and titrated upwards based on clinical effects and trough levels." (p. 59).

20. This is the year when this researcher started his hormonal transition.

21. JOCKENHÖVEL, F, et al., "Comparison of long-acting testosterone undecanoate formulation versus testosterone enanthate on sexual function and mood in hypogonadal men", in European Journal of Endocrinology, Vol. 160, 2009, p. 816. As stated by the researchers, after "the first injection, a second dose is given 6 weeks later and in the vast majority of patients an injection every 12 weeks (with variations between 11-13 weeks) maintains plasma testosterone in the physiological range." (Ibid.)

22. Normal range for a biological male is 290 to 900 nanograms per deciliter (ng/dl). Around $500 \mathrm{ng} / \mathrm{dl}$ is the highest Female-to-Male achievable.

23. LEVY, Andrew, CROWN, Anna, and RUSSEL, Reid, "Endocrine intervention for transsexuals", in Clinical Endocrinology, Vol. 59, 2003, p. 416.

24. Gender Recognition Act (GRA), London, 2004, Ch. 7 has been defined as an "Act to make provision for and in connection with change of gender." [p. 1] Online: http:// www.legislation.gov.uk/ukpga... (Accessed: 02.04.2012).

25. There is plenty of evidence noted in UK and US research reports and reviews, such as theTrans Research Review (MITCHELL, Martin, and HOWARTH, Charlie, Trans Research Review, Manchester, Equality and Human Rights Commission, 2009), the "Engendered Penalties: Transgender and Transsexual People's Experiences of Inequality and Discrimination" (WHITTLE, Stephen, TURNER, Lewis, and AL-ALAMI, Maryam, "Engendered Penalties: Transgender and Transsexual People's Experiences of Inequality and Discrimination", in The Equalities Review, 2007) or the most recent US-based Injustice at Every Turn: A Report on the National Transgender Discrimination Survey (GRANT, Jaime M., et al., Injustice at Every Turn : A Report of the National Transgender Discrimination Survey, Washington, National Center for Transgender Equality and National Gay and Lesbian Task Force, 2011). Moreover, this researcher, in a patient's capacity, has had direct negative experience over the last ten years. This has involved documented incidents with medical professionals, complaints and, subsequently, the necessity for changes in his medical provision. The reasons have ranged from unprofessional attitudes in doctors, including inappropriate comments and "jokes", all the way to downright abuse in the guise of "research" purposes.

26. WHITTLE, Stephen, TURNER, Lewis, and AL-ALAMAI, Maryam, "Engendered Penalties: Transgender and Transsexual People's Experiences of Inequality and Discrimination", in Equalities Review, 2007. Online: http://www.pfc.org.uk/pdf/Engendere... (Accessed: 27.10.2010). 
27. Cf. Gender Recognition Act (GRA), Ch. 7, London, 2004, p. 1. Online: http:// www.legislation.gov.uk/ukpga... (Accessed: 02.04.2012).

28. The author began his own pre-transitional research and experimental work on FTM Voice in 2002-2003.

29. VAN BORSEL, John, et al., "Voice problems in female-to-male transsexuals", in International Journal of Language and Communication Disorders, Vol. 35, № 3, 2000, p. 427.

30. The devised method for the transitional stage can be found in CONSTANSIS, Alexandros N., "The Changing Female-to-Male (FTM) Voice", art. cit., pedagogical notes 1 and 2. The link is: http://www.radical-musicology.org.u... (Accessed : 19.10.2012).

31. Cf. Adolescent voices : 'Pattern Two' of Swanson scale is dedicated to voices experiencing rapid puberty. This happens when the voice drops "almost overnight into the deepest regions of the bass clef (and) the treble tones disappear." SWANSON, Frederick J., "The young male with a changing voice", in NATS Bulletin, Vol. 38, № 1, 1981, p. 33. These boys were even described by the 1981 pioneering researcher as "neglected, discarded, wasted, lost singers." (Ibid.). Swanson, however, was among those who recommended in 1984 that the results of this rapid change can only be remedied by the introduction of good vocal habits during the changing period (Swanson, Frederick J., "Changing voices : Don’t leave out the boys", in Music Educators Journal. Vol. 70, № 5, 1984, p.47). This has been corroborated in more recent research by John Cooksey, who, however, also recognised that periods of "rapid change" can make "vocal coordinations" difficult and the "voice quality [...] inconsistent." Cooksey, John M., and Welch, Graham F., "Adolescence, singing development and national curricula design", in British Journal of Music Education, Vol. 15, № 1, 1998, p. 108. In the adult female voice, we have a very clear example of the effect of hormonal differentiation in the "premenstrual voice syndrome", where the singers experience results, such as "vocal fatigue, decreased range with a loss of pianissimo (and a) flat colourless timbre". Abitbol J, Abitbol P, Abitbol B, "Sex hormones and the female voice", in Journal of Voice, Vol. 13, № 3, 1999, p. 437. The above symptoms are becoming more prominent in the case of vocal syndrome of the menopause and can include, apart from the above, the lowering of vocal intensity and a loss of timbre in the spoken and singing voice. (Abitbol p. 439) Finally, as stated by Gugatschka, the aging male voice is "another aspect of the human body prone to be affected by decreasing levels of sex hormones occurring during the aging process." Gugatschka, Markus, "Sex hormones and the elderly male voice", in Journal of Voice, Vol. 24, № 3, 2010, p. 372.

32. For this reason, a more carefully-designed support for transsexuals is recommended over that period. This would need to ensure, apart from continued employment for the transitioning individuals, their safe housing as well as protection from violence, harassment and discrimination. The provision plan should be drawn by specialised-inthe-field practitioners, such as medics and social workers, and could be similar to the ones applied to other groups in need of protected accommodation and employment. However, like all protected groups, transsexuals would deserve to be treated in a way that does not negate their individual experiences. The protected groups should also be taking an active part at training and promoting equality and diversity in society.

33. Cf. CONSTANSIS, Alexandros N., Hybrid Vocal Personae, PhD Thesis, York (UK), University of York, 2009, and id., "The Changing Female-to-Male (FTM) Voice", art. cit. Online: http://www.radical-musicology.org.u... (Accessed : 19.10.2012).

34. CONSTANSIS, Alexandros N., Hybrid Vocal Personae, op. cit., p. 280. 
35. According to Grove Music Online, Art Song is a "song intended for the concert repertory, as opposed to a traditional or popular song. The term is more often applied to solo than to polyphonic songs." "Art song", in Grove Music Online, Oxford Music Online, http://www.oxfordmusiconline.com/su..., 2012 (Accessed : 07.08.2012).

36. The case of the late Giuseppe Di Stefano (1921-2008), a lyric tenor, is a classic example from the operatic world. His taking on "dramatic roles that required him to expand his sound (especially at the top) beyond the reach of what turned to be a limited technique" (POTTER, John, Tenor: History of a Voice, New Haven and London, Yale University Press, 2009, p. 172-173) have been directly associated with the singer's career spanning "little more than fifteen years." (Potter, p. 173)

37. For an explanation of the specific term as well as its general background, see footnote no 41 .

38. Case Studies $1 \& 2$.

39. However, electric keyboard / pianos (e.g., Clavinova type) whose dynamics and volume can be adjusted accordingly are even more suitable than instruments, such as the guitar. This is because they allow for the replication and reliability of experimental and / or performance conditions.

40. A reliable though costly example of amplification is the SoundField DSF-1 digital microphone system. Nonetheless, more economical solutions, depending on each singer's style and repertoire, can also be effective.

41. Constansis re-defined concepts such as "hybrid voice" and introduced terms such as "hybrid vocal persona". Similarly to Sundberg who defined "voice sounds" as strictly originating "from an airstream from the lungs that is processed through the vocal folds and then modified by the pharynx, the mouth, and perhaps also the nose cavities" (SUNDBERG, Johann, The Science of the Singing Voice, DeKalb, IL, Northern Illinois University Press, 1989. p. 1), Hybrid Vocal Personaedeal with the results of actual vocal personae and not those of technologically manipulated or "Designer" voices (CAMERON, Deborah, "Designer Voices", in Critical Quarterly, Vol. 43, № 4, 2001, p. 81-85). In addition, unlike other musicological definitions, the terms "hybrid vocality" and "hybrid vocal personae" tend to focus on the effects of non-binarian, i.e., non-strictly "male" or "female", endocrinological and gender formation in singing vocality. Subsequently, these particulars are integrated and reassessed under a wide range of Humanities perspectives, apart from Musicological ones, with the incorporation of recent developments in Gender / Queer Theory and Social Sciences. This allows the drawing together of vocal personae from a variety of contexts without resulting in the pathologisation of human variation. Hybrid vocal personae, despite the presence of terminological changes, have been discovered in all civilisations. As such, their phenomenon has not been attributable to parameters, such as chronological and local convergence or divergence. A full explanation as well as the philosophical background of the terms hybrid and hybridity has been provided in Constansis, Alexandros N., Hybrid Vocal Personae, op. cit., p. 21-25.

42. The above has been demonstrated in Case Studies 1 \& 2 .

43. Appoggio is an Italian singing term derived from the verb appoggiare. According to Oxford Language Dictionary (http://www.oxfordlanguagedictionari...), the word has several meanings. Those most relevant to singing are associated with leaning on and resting (something) on. Even though, in the past, appoggiare used to be associated with "support", this inaccurately translated definition has been deemed to be rather confusing 
and restrictive and, as such, better avoided. The appoggio's primary aims are to utilise and engage the majority of the body in order to produce better breath management (i.e., elongated breath cycle and capacity) as well as tonal clarity and accuracy.

44. The above participants had been taught the exercise (Vaccaj, Lesson 1: Part 1) during their participation in the Changing Voice Stage (2010-11). All participants of the Singing FTM Voice programme (Changing, Developing and Advanced Stages) follow the same detailed method of instruction.

45. See Appendix.

46. Cf. CONSTANSIS, Alexandros N., "The Changing Female-to-Male (FTM) Voice", art. cit. Online: http://www.radical-musicology.org.u... (Accessed: 19.10.2012).

47. The latter would have introduced unnecessary differentiation and shifted the focus of attention to secondary parameters, such as mispronunciation and accent. As such, it would have likely compromised the study design, as well as validity, reliability and generalisability of the results.

48. Sonority here means the "quality of tone produced" by each singer. "Sonority", Latham, Alison (ed.), The Oxford Companion to Music, online www.oxfordmusiconline.com/su... (Accessed: 23.08.12).

49. During their participation in Changing Voice stage, all participants receive the same detailed training on this exercise. The tuition not only explains what is required in terms of technique and performance but also what is expected in terms of a listening audience. The four of them had been among the most advanced of their group and had already demonstrated their advanced listening ability. As such, and for the demands of this exercise, the four singers were able to act as trained listeners.

50. For the purposes of these Studies, this researcher created four anonymous but numbered folders (each participant was allocated an individual number, which was not known to them). As a result, each folder ended up containing four files; for example, A1, A2, A3, A4, B1 etc.

51. The participants, due to online tuition, only met after the end of Studies 1 and 2.

52. To this, the notes' values are also taken into consideration. As such, one quaver counts as 0.5 , one crotchet as 1 and, finally, one minim as 2 points.

53. The terms biomale and cisgender baritones are used interchangeably.

54. LEWCOCK, Ronald et al. (signed by Sundberg, Johan), "Acoustics", Grove Music Online, Oxford Music Online, http://www.oxfordmusiconline.com/su... (Accessed: 25.08.12).

55. In this case, the score demands from the singer to perform the range of an octave and a half with extensive use of breath control, utilisation of the technique of legato as well as the application of a range of dynamics against a piano accompaniment also utilising the above means of expression.

56. The sets of recorded results, apart from being subjected to self-assessment, peerreview and researcher evaluation, are also going to be assessed using software, such as Sygyt - Overtone Analyser (http://www.sygyt.com/).

57. This implies the periods from August 2002 and until March 2003 (preparation stage) and from March 2003 and until March 2004 (completion of first participation of Changing Female-to-Male Voice programme).

58. The majority of the participants of this programme are connecting from intercontinental locations. 
59. As discussed in CONSTANSIS, Alexandros N., Hybrid Vocal Personae, op. cit., p. 280, the method of externally-obtained laryngeal measurements can only provide us with an indication and not the full picture of vocal fold development. Based on the programme's limited resources between 2003 and 2006 - a factor directly related to the researcher's trans status- and the variety of geographical locations, this obtaining of these measurements was found to be the most feasible methodological approach. Moreover, this was an attempt to replicate the exact conditions of the first participation (2003-2004) when measurements had been obtained before and, regularly, after the beginning of testosterone administration. The participants' data, even with its limitations, has provided the researcher with a reasonable indication of laryngeal development.

60. It is in the researcher's plans to continue working on this study until the existing findings and results are fully replicated and confirmed.

61. That is from native oestrogens to bioidentical testosterone.

62. This included FTM and MTF singers as well as cisgender women's vocalists.

63. Despite the presence of several participants of the Developing Voice section of this research project, none of them can offer the number of Constansis' years of combined data collection.

64. That is presented with less noticeable peaks and troughs in the given period.

65. As stated, we only have long term experience of "more than 8 years with TU in 22 hypogonadal men". YASSIN, A.A, and SAAD, F., "Treatment of sexual dysfunction of hypogonadal patients with long-acting testosterone undecanoate (Nebido ${ }^{\oplus}$ ", in World Journal of Urology, Vol. 24, 2006, p. 640, based on ZITZMANN, M.N.E, "Long-term experience of more than 8 years with a novel formulation of testosterone undecanoate (Nebido) in substitution therapy of hypogonadal men", in Aging Male, Vol. 9 (suppl. 1), 2006, p. 5, and NIESCHLAG, Eberhard, and BEHRE, Hermann M. (eds), Testosterone, action, deficiency, substitution, Cambridge, Cambridge University Press, 2004.

66. Cf. http://www.patientsville.com/medica... (Accessed: 25.10.12).

67. T'SJOEN, Guy, et al., "Impact of Voice in Transsexuals", in International Journal of Transgenderism, Vol. 9, № 1, 2006, p. 4.

68. The term is defined as an "increase in red cell count, haemoglobin and packed cell volume (PCV) above the normally accepted levels." HOWARD, Martin R., and HAMILTON, Peter J.,Haematology, 3rd Ed., Edinburgh, London and New York, Churchill Livingstone, 2008, p. 64. Polycythaemia is reported as "a rare complication in female-to male transsexual persons." T'SJOEN, Guy, Psycho-Endocrinological Aspects in Aging Males and Transsexual Persons, PhD Dissertation, Ghent, Belgium, University of Ghent, January 2006, p. 49.

69. We should underline here that the researcher used to suffer from secondary and not primary polycythaemia or polycythaemia vera, "an acquired myeloproliferative disorder [... ] associated with thrombocytosis, leukocytosis and splenomegaly." James, C, Ugo, V, Le Couedic, J-P et al., "A unique clonal JAK2 mutation leading to constitutive signalling causes polycythaemia vera", inNature, Vol. 434, April 2005, p. 1144.

70. Cf. The anticipated side effects are among the reasons why the most renowned specialists within the field suggest that "cross-sex hormone levels (should) be maintained in the normal physiological range for the desired gender." HEMBREE, W.C, et al., 
"Endocrine Treatment of Transsexual Persons: An Endocrine Society Clinical Practice Guideline”, in Journal of Clinical Endocrinology and Metabolism, Vol. 94, № 9, 2009, p. 3133.

71. The problematic third was from $A^{\prime}$ to $c$, according to Helmholtz notation (Ex.1 - black font colour).

72. A limited number of pre-transitional FTM participants were also helped in this context.

73. See Ex. 1 - the interval of a fifth (red font colour), $G$ ' to $d$, demonstrates the extended "gap".

74. The discrepancy has been assessed, apart from during individual lessons, by listening to the vocal quality of anonymised recorded samples from all participants. Moreover, as demonstrated in Case Study 1, specific music phrases were sung and recorded at original (i.e., an officially published version) and after their transposition to three lower and more suitable keys.

75. This effect is, understandably, aggravated when the voice is also affected by health and other similar issues.

76. In May 2013, the reader will be able to find updated information as well as samples of the researcher's most recent recordings on www.alexandrosconstansis.com. The background of two of the July 2011 recordings has also been discussed in published works, such as ADLER, Richard K., CONSTANSIS, Alexandros N., and VAN BORSEL, John, "Femaleto-Male Transgender / Transsexual Considerations", in ADLER, Richard K., HIRSCH, Sandy, and MORDAUNT, Michelle (eds.), Voice Therapy and Communication for the TG/TS Client, 2nd Edition, San Diego, CA, Plural Publishing, Inc., 2012, p. 160-162.

77. PARKER, Emma, “The Real Thing: Transsexuality and Manhood in Rose Tremain's Sacred Country", in Women: A Cultural Review, Vol. 18, № 3, 2007, p. 303 and p. 312.

78. Despite the presence of professional popular / folk style performers, such as Eli Conley, the only "loss" of vocality we can truly associate with FTMs is the unsupported popular style of singing when using the low "male" register (please note that the issue does not exist when using a falsetto-like projection). The rest of vocal ability can be improved or even remedied with the correct initial HRT and continuing exercising regime. The so-called 'loss' has been associated with one significant restriction: unless the FTM singer applies a classical singing technique called 'laryngeal drop', he cannot achieve a sufficient vocal folds' closure and, subsequently, a clear and projectable tone, especially when using his 'chest' voice registers. This particular is more noticeable in singers performing live and without technical support, such as amplification and equalising. The effects of this aspect have been demonstrated in Case Study 2.

79. LEWIS, Rachel, "What's Queer about Musicology Now?", in Women and Music: A Journal of Gender and Culture, Vol. 13, 2009, p. 43-53.

80. BONENFANT, Yvon, "Queer Listening to Queer Vocal Timbres", in Performance Research: A Journal of the Performing Arts, Vol. 15, № 3, 2010, p. 74.

81. BUTLER, Judith, Undoing Gender, London, Routledge, 2004, p. 65.

82. WILCHINS, Riki Anne, Read my lips: Sexual subversion and the end of gender, New York, Firebrand, 1997, p. 155.

83. CONSTANSIS, Alexandros N., "It's up to us to Make our Voices Sing", in Voiceprint Australian Voice Association, 2008, p. 6. 


\section{ABSTRACTS}

Few types of human voice can be considered to be on the edges of vocality and queer theory more than the Female-to-Male transsexual vocality or transvocality. Even though the characteristics of Female-to-Male (FTM) vocality, speaking or singing, are often presented as the direct result of medical developments in endocrinology, scientific studies were not particularly concerned with singing results before 2002. On the contrary, transsexual men were warned about the dramatic effects in their singing vocal personae. This well established medical evaluation, which has recently begun to be scientifically challenged, can be attributed to three important elements: Abrupt hormonal administration, the care provision for transsexuals and general attitudes towards transvocality. Similarly, post-transition, changes in the hormonal regime may cause further complications for the FTM singer. We are going to discuss this in detail through vocal and general health information as well as considering two case studies based on four participants. In terms of specific musical practice, the knowledge derived from these studies will prove valuable to singers as well as composers and music coaches. This is because, when Femaleto-Male singers know the particulars of their individual instruments, the composers may be more interested to write for them and music coaches more willing to listen. Thus, the transmale hybrid vocal personae would be able to achieve freedom from binarian standards and, therefore, respect for themselves and their audiences.

Peu de types de voix humaines peuvent être considérés comme étant aux confins de la vocalité et de la théorie queer, mais celui de la vocalité transsexuelle de la femme vers l'homme (FTM), à savoir la transvocalité, en serait le meilleur exemple. Bien que les caractéristiques de la vocalité FTM, que ce soit la parole ou le chant, furent souvent présentées comme étant le résultat direct des développements médicaux en endocrinologie, les études scientifiques ne s'intéressèrent pas particulièrement aux résultats du chant avant 2002. Au contraire, les hommes transsexuels furent alertés des effets dramatiques des traitements sur leur vocalité. Cette évaluation médicale bien établie, qui a récemment fait l'objet de contestations scientifiques, peut être attribuée à trois éléments d'importance : l'administration hormonale abrupte, la mise à disposition des soins pour les transsexuels et les attitudes générales envers la transvocalité. De façon similaire, dans la phase post-transition, les changements dans le régime hormonal peuvent causer des complications plus profondes pour le chanteur FTM. Nous discuterons cela en détail en nous appuyant sur des informations d'ordre général sur la voix et la santé, ainsi que sur deux études de cas basées sur quatre participants. Du point de vue de la pratique musicale, les résultats de ces études se révèleront précieux pour les chanteurs, de même que pour les compositeurs et les professeurs de musique. Car, lorsque les chanteurs FTM connaissent les particularités de leur instrument individuel, les compositeurs peuvent être davantage amenés à écrire pour eux, et les professeurs de musique plus disposés à les écouter. Ce type particulier de vocalité pourrait ainsi s'émanciper des standards binaires et permettrait aux chanteurs en transition d'acquérir une forme de respect pour eux-mêmes et de la part du public. 


\section{INDEX}

Mots-clés: vocalité hybride, théorie queer, transsexuel, voix FTM

Keywords: hybrid vocality, queer theory, transsexual, female-to-male singing voice

\section{AUTHOR}

\section{ALEXANDROS N. CONSTANSIS}

Alexandros N. Constansis has been working in the singing voices' field since 1980. His performing career in ballads / art songs and later classical / baroque genres spanned almost two decades. In addition, he also focused on Music Conservatoire teaching and early singing research, which acquired a more academic focus in 1995. During that year, his repertoire, consisted of roles originally written for the castrati singers of the "Baroque" era, became also the starting point of his study on hybrid vocality, which developed in its later more academic format in 2000 . Since 2002-2003, year of his own journey affirmation, Constansis has been focusing his attention on Female-to-Male and, later, Male-to-Female trans singing personae. These have been examined alongside existing postgraduate research on vocality formed by non-binarian hormonal variations (e.g., Natural Male Sopranos). Since 2005 the researcher has been describing all abovementioned singers under the umbrella term "Hybrid Vocal Personae". The term, first presented at the 2005 British Forum of Ethnomusicology (BFE) Conference, has also been the title of his doctoral dissertation. His PhD was awarded in 2010 (University of York, U.K). Constansis is currently an Independent Researcher and Scholar. 